\title{
Sexualidade e Síndrome de Down: combinação possível?
}

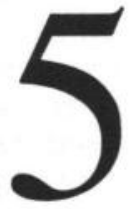

\author{
Talita Borges Castelão* \\ Pedro Jurberg** \\ Márcio Ruiz Schiavo***
}

\section{RESUMO}

O artigo trata da sexualidade da pessoa com síndrome de Down, atentando para as implicações relacionadas à vivência da mesma no contexto de deficiência mental. Acreditando que não existe comprometimento capaz de impedir a interação da pessoa com síndrome de Down no âmbito social, inter-relacional, afetivo e sexual, este estudo bibliográfico apresenta um breve histórico sobre a síndrome, aspectos de ordem biológica e social, finalizando com a questão do casamento e reprodução. Embora a síndrome de Down seja a alteração cromossômica mais comum em humanos, o processo de inclusão é lento. A pessoa com síndrome de Down vivencia sua sexualidade com restrições do contexto social no qual está inserida.

* Mestre em Sexologia pela Universidade Gama Filho. Professora do Centro Universitário Adventista de São Paulo (UNASP).

** Doutor em Ciências. Professor do mestrado em Sexologia da UGF e Pesquisador do Instituto Oswaldo Cruz.

*** Doutor em Comunicação Social. Professor do mestrado em sexologia da Universidade Gama Filho. Presidente da Sociedade Brasileira de Sexualidade Humana-SBRASH.

e-mail: talita@iae.sp.br

Recebido em 17.11.01 mschiavo@comunicart.com.br

Aprovado em 03.12.01 
A síndrome de Down (SD), alteração cromossômica mais comum em humanos, têm sido alvo de estudos aprofundados nos últimos anos. Conquanto se tenha avançado muito no conhecimento em relação à $\mathrm{SD}$, pouco tem sido a participação da sociedade nesta questão. Não há dúvidas que as mudanças até aqui vistas, são resultado do empenho de pais e alguns profissionais que se fizeram responsáveis pelo assunto.

Em relação a pessoas que possuem deficiência mental mais especificamente, o tema sexualidade sempre preocupou pais e profissionais de atendimento. Na síndrome de Down, esta preocupação cresce diante de características genéticas peculiares capazes de comprometer sua reprodução. De qualquer modo, o ponto central de atenção não está exatamente nas questões de ordem genética. A socialização, desejos, anseios e frustrações sobre a afetividade que permeiam a vida dessas pessoas requerem atenção especial por parte de todos que lidam com elas.

Ainda se conserva na sociedade ocidental uma histórica interdição ao sexo e à sexualidade, considerada atributo de pessoas adultas e saudáveis ignorando as manifestações que acompanham o desenvolvimento normal. Assim, o deficiente mental está na categoria dos que não têm maturidade necessária para assumir socialmente a condição de ser sexuado. Mas, esta não é a realidade. $O$ deficiente atua e percebe sua sexualidade dentro da etapa de maturidade psico-sexual correspondente à sua idade mental. (Moreira, 1990, p. 14).

Para compreendermos algumas implicações relacionadas ao exercício da sexualidade na síndrome de Down, faremos a seguir um breve histórico sobre a síndrome, contemplando aspectos de ordem biológica e social. Finalmente, analisaremos a questão do casamento e reprodução, ampliando a abordagem para sexualidade e deficiência.

\section{BREVE HISTÓRICO DA SÍNDROME DE DOWN}

Segundo Pueschel (1998) o registro mais antigo da SD procede das escavações de um crânio saxônio, datado do século VII, que apresentava modificações estruturais vistas com freqüência em crianças com SD. Algumas pessoas acreditam que a síndrome de Down tenha sido representada no passado em desenhos e esculturas como as esculpidas pela cultura Olmec há quase $3 \mathrm{mil}$ anos, onde se reproduz o fenótipo característico da síndrome.

Embora se considere a síndrome de Down tão antiga quanto a humanidade, foi apenas em 1866 que John Langdon Down descreveu o conjunto de seus sinais e sintomas característicos. Levando em conta a aparência oriental das pessoas com síndrome de Down e sua deficiência mental, J. L. Down deduziu que as pessoas estudadas por ele, estavam, de alguma forma, 
regredindo a um tipo racial mais primitivo, o que caracterizaria um retrocesso no caminho normal da evolução dos seres vivos.

Neste período Charles Darwin acabava de lançar seu livro Origin of Species, o que dificultou a aceitação da condição descrita. Down deu-lhe, então, o nome de mongolian idiotas, denominação que, sofrendo mutações lingüísticas, chegou ao Brasil como idiotas mongolóides (Pueschel, 1998). Tal designação, contudo, há muito tempo não é usada para essa alteração, pois é carregada de preconceito, tendo em vista o fato de se basear nas semelhanças físicas características do povo da Mongólia, considerado na épo$\mathrm{ca}$, uma raça inferior física e intelectualmente. Atualmente prefere-se adotar o termo síndrome de Down.

As alterações na síndrome de Down são causadas em 95\% dos casos pela presença de um cromossomo extra, o de número 21 (cariótipo: $47, \mathrm{XX}$ ou $X Y+21)$. Os $5 \%$ restantes referem-se aos casos de translocação e mosaicismo (Antonarakis \& Down Syndrome Collaborative Group, 1991). Coube a Lejeune, Gautier e Turpin (1959), a associação entre as características da síndrome e alterações cromossômicas. Pela primeira vez foi constatado que alterações no material cromossômico poderiam causar retardo mental e anomalias congênitas graves (Gelehrter \& Collins, 1992).

Alguns sinais característicos da SD são hipotonia, pescoço adiposo e grosso, orelhas com baixa implantação, língua protrusa, braquicefalia, braquidactilia, clinodactilia do quinto dedo, prega palmar única, prega epicântica e baixa estatura. Outras complicações mais graves são a deficiência mental e problemas cardíacos. Cooley e Graham (1991), observaram que em 1965 cerca de $50 \%$ das pessoas com a síndrome faleciam até os cinco anos de vida, devido a doenças cardíacas. Hoje, metade dos pacientes sobrevive mais de 50 anos e um em sete ainda está vivo aos 65 anos (Baird \& Sadovnick, 1989), provavelmente por realização precoce de cirurgias corretivas.

A deficiência na síndrome de Down é a conseqüência mais prejudicial. Mustacchi (1998) citando a Organização Mundial de Saúde (OMS) relata a ocorrência de cerca de $10 \%$ de deficientes na população brasileira, sendo, $50 \%$ desses, portadores de deficiência mental. A prevalência da síndrome de Down na população é de menos de $2 \%$ e corresponde a cerca de $18 \%$ do total de deficientes mentais em instituições.

A possibilidade de nascer uma criança com síndrome de Down aumenta principalmente com a idade materna: em torno dos 20 anos é de $1: 1500$, subindo para 1:380 aos 35 anos e para quase 1:28 aos 45 anos (Connor \& Ferguson-Smith, 1997). Castilla et al. (1998), também concordam com um aumento significativo no risco de nascimento da criança com SD após a idade materna de 35 anos. Uma explicação para isso é a formação dos óvulos ainda no período pré-natal, que ficam expostos durante muito tempo a agentes ambientais perigosos que podem provocar erros durante a divisão meiótica. A probabilidade de reincidência da síndrome é de cerca de $1 \%$. Nos EUA e Canadá, $50 \%$ ou mais das mulheres grávidas com idade acima de 35 anos têm a prática de realizar diagnóstico pré-natal para análise 
dos cromossomos fetais, apesar de apenas $1 \%$ dos fetos testados apresentarem trissomia do 21 (Smith, 1985).

Não há nenhuma variação racial significativa na incidência da síndrome de Down (Lau et al., 1988). Contudo, os efeitos das diferenças raciais podem, em determinado grupo, ter pouco valor para o diagnóstico. A inclinação mongolóide das fendas palpebrais em pacientes japoneses com SD têm valor nulo entre eles, apesar da grande importância desse sinal para o diagnóstico dessa cromossomopatia em caucasóides.

Segundo Boletim Informativo do Projeto Down (1982), nas últimas décadas algumas crianças com síndrome de Down foram submetidas à cirurgia plástica facial. Isto visa amenizar sinais característicos da síndrome como as pregas epicânticas, eixo oblíquo das pálpebras, protrusão lingual, ponte nasal achatada e queixo pequeno e recaído. Essas cirurgias podem ser funcionais ou estéticas. Cabe aos pais a decisão de submeter ou não a criança à cirurgia. Muitos deles acreditam que isso facilita a integração da mesma, à medida que a liberta do estereótipo que a envolve frente a colegas, professores e sociedade em geral, dando-lhe portanto, maior possibilidade para que mostre sua personalidade e potencial, já que sua aparência e maneira de falar dificultam isso. Amenizar as características da síndrome, nestes casos, parece sobrepor a necessidade de uma maior compreensão e aceitação da estrutura do desenvolvimento cognitivo das crianças com SD.

O QI na síndrome de Down costuma estar entre 25 e 50 quando o indivíduo tem idade suficiente para fazer o teste. Mas isso não impede que essas pessoas sejam felizes e mesmo auto confiantes a despeito de suas limitações. Não são poucos os esforços de pais e profissionais no sentido de promover a inclusão da pessoa com síndrome de Down na sociedade. Segundo Werneck (1997), o movimento pela sociedade inclusiva é internacional, tem regras bem definidas e foi explicitado pela primeira vez em 1990, pela Resolução 45/91 pela Assembléia Geral das Nações Unidas que defendia uma sociedade para todos, partindo do princípio de que "todas as pessoas têm o mesmo valor" (p. 21).

Apesar de não haver cura para a síndrome de Down a qualidade de vida dessas pessoas tem sido melhorada significativamente. A instalação do National Down Syndrome Congress em 1973 nos EUA e a organização de movimentos similares em todo o mundo, defendendo o tratamento e oportunidades de vida dos pacientes e suas famílias são responsáveis por esta melhoria (Colley \& Graham, 1991).

\section{CASAMENTO E REPRODUÇÃO NA SÍNDROME DE DOWN}

Amenizadas as diferenças entre as pessoas com a síndrome sobre questões de aprendizagem e tratamento a eventuais problemas de saúde, 
surge uma nova questão proposta por Moreira (1998): "não são raros os namoros e até casamentos na síndrome de Down” (p. 2).

Brown (1993), discute a questão do casamento e apresenta entrevistas de algumas pessoas com idades variando entre 30 e 40 anos. Nestes exemplos o parceiro não possui a mesma síndrome, mas algum tipo de comprometimento mental, como por exemplo, a paralisia cerebral. Grande parte dos casamentos são felizes e de longa duração, como o caso de Pat e Jim, casados desde de fevereiro de 1973. Outros já haviam passado pelo divórcio.

No Brasil já existem alguns relatos de casamento de pessoas com síndrome de Down. Um deles é o de Olga Mansur (26 anos), que pinta, faz livros de poesia e trabalha. Casada com Paulo (40 anos), portador de deficiências motoras, leva uma vida independente tendo conseguido destaque como pintora no mercado de arte com quadros que alcançam até $\mathrm{R} \$ 1,5$ mil (Albuquerque \& Ramalho, 1999).

Assumpção e Saprovieri (1987), demonstram cautela ao falar sobre o casamento para deficientes mentais, considerando o acompanhamento de oito casos na APAE de São Paulo, em que os casamentos se desfizeram após uma duração máxima de cinco anos de relacionamento. As razões para os rompimentos priorizavam a falta de condições financeiras para sobrevivência.

Em países ricos, casais nestas condições recebem auxílio do governo; é o que relatou Brown (1993) no III Congresso Internacional de Síndrome de Down na cidade de Orlando-Flórida [EUA]. Estes casos mostram que a pessoa com síndrome de Down pode ter uma vida boa, muito provavelmente melhor que uma pessoa comum e pobre. Esta foi a idéia explorada pelo publicitário Nizan Guanes, numa campanha institucional premiada em 1998 nos festivais de Cannes e de Nova York.

$\mathrm{O}$ vídeo mostrava duas crianças brincando num carrossel. Era dito que um deles ia à escola, tinha aulas de piano e fazia natação, enquanto que o outro não podia fazer nada disso. O primeiro menino possuía síndrome de Down. E o seu amigo era uma criança comum, mas que vivia na rua. $\mathrm{O}$ vídeo finalizava com o seguinte apelo: "Milhões de crianças brasileiras precisam de sua ajuda. Crianças com síndrome de Down apenas precisam do seu respeito. O preconceito é a pior síndrome" (Albuquerque \& Ramalho, 1999, p. 90).

Outra situação interessante foi relatada no filme The Eighth Day $(O$ oitavo dia) de Philippe Godeau, onde numa cena, Georges e Natalie, ambos com SD conversam sobre sexo:

- Não é permitido.

- O quê?

- Você sabe... fazer amor.

- Quem disse?

- Meu pai disse.

- Mas seu paifaz. 


\section{- É diferente. Ele é normal, trabalha... é diretor, tem carro e tudo. \\ - Mas com ele, não quero.}

Em muitos sentidos, parece que a condição de vivência da sexualidade depende muito mais do contexto financeiro que do comprometimento biológico em si.

Para a pessoa com $S$. Down, a puberdade e a maturação sexual são comparáveis à população em geral. Nas meninas a menstruação ocorre como em outras jovens, exceto em casos de hipotireoidismo ou problemas crônicos de saúde, em que pode ocorrer atraso na puberdade. Cerca de $40 \%$ tem ovulação normal, enquanto que $30 \%$ apresentam irregularidade menstrual. (Moreira, 1998, p. 2).

Johannisson et al. (1983), demonstraram a diminuição na capacidade de formar espermatozóides funcionais além de observar o comportamento anormal do cromossomo 21 extra na prófase da meiose. É possível que na $\mathrm{SD}$, exista uma associação entre os cromossomos sexuais (complexo XY) e o cromossomo 21 extra, capaz de causar a esterilidade para os homens. Mas isto não compromete, necessariamente, o desenvolvimento das características sexuais secundárias, funcionalidade ou desempenho sexual. Sheridam et al. (1989) relatam o primeiro caso de paternidade na síndrome de Down, seguido de aborto espontâneo, mas com nova gestação após dois anos, resultando num filho sem alteração cromossômica. O mesmo estudo descreve, apesar da redução no número de folículos, 26 mulheres sem mosaicismo, que em 29 gestações produziram 10 filhos com SD, dois abortos espontâneos e 18 filhos sem alterações cromossômicas, incluindo um par de gêmeos idênticos.

Existem outros relatos de reprodução em mulheres com SD sem a confirmação de paternidade proveniente de um homem com a síndrome (Thompson, 1961; Jagiello, 1981). Zühlke et al. (1994) relatam estudo sobre a reprodução de homem com SD dando origem a uma menina normal.

Diante da possibilidade reprodutiva para as pessoas com SD, é importante analisar as possibilidades de combinação dos cromossomos que formam os gametas (óvulos e espermatozóides) e do resultado das combinações desses cromossomos após um relacionamento sexual. Os Quadros 1 e 2, baseados em Moreira (1998), mostram que na reprodução de pessoa com SD e outra sem a síndrome, existe $50 \%$ de chance de nascerem filhos comuns; em contrapartida, na reprodução de um casal possuidor de SD, considerando fertilidade para ambos, esta chance decai para $25 \%$.

Certamente estas informações precisam ser repartidas com o casal e sua família a fim de que escolham o caminho que querem trilhar sem serem surpreendidos por uma gravidez indesejada. Edwards (1998), diz que no 
passado era freqüente a realização da esterilização em mulheres com síndrome de Down. Esta prática controvertida desde os anos 70, foi atenuada por meio de ação legal, dando lugar a programas educacionais que ensinam sobre direitos e responsabilidades no campo da sexualidade, e ajudam os pais na abordagem do tema.

\section{SEXUALIDADE E DEFICIÊNCIA}

Para falar sobre sexualidade num contexto de síndrome de Down é preciso compreender como o indivíduo deficiente mental (DM) se estrutura em termos de personalidade. A sexualidade é fator inerente à pessoa e por isso vai se manifestar independente de ensinamento. Amezúa apud Reche (199-) afirma que não se pode viver sem sexo como não se pode viver sem personalidade. As situações de desejo e prazer na criança percorrem um universo simbólico, que tende a se transformar em atos na vida adulta, quando então é possível satisfazer as pulsões originais. Schimidt (1998) afirma que na infância se troca a satisfação das pulsões imediatas pela promessa da realização futura.

A estruturação do sujeito psíquico passa pela relação de desejo com o outro. É necessário que haja prazer nesta vivência e ainda, que haja um corte - geralmente feito pelo pai - na primeira relação dual (mãe/filho), para que uma nova perspectiva de envolvimento com o mundo externo surja (Freud, 1972).

Quando nasce uma criança com deficiência o desejo materno em relação ao bebê já está comprometido, pois no lugar do filho ideal imaginado surge um intruso usurpador dos projetos futuros. Leva tempo até a mãe elaborar o luto pelo bebê perfeito que não nasceu. $\mathrm{O}$ desejo da mãe em relação ao novo filho terá de ser revisto. A interação que se estabelece entre indivíduos deficientes e a família pode se modificar, mas a recuperação da pessoa deficiente mental começa pela educação dos pais. Solnick e Stark (apud Bernard \& Erikson, 1978) comentam sobre problemas que os pais do indivíduo deficiente é forçado a encarar:

Enfrentar a realidade externa de uma criança com defeitos congênitos e a realidade interna de sentir a perda de uma criança normal desejada requer muito trabalho mental. Essa tarefa psiquica é vagarosa e emocionalmente, penosa. Cresce através da descarga gradual e repetida de intensos sentimentos e memórias. Essas reações mentais e emocionais capacitam os pais para reconhecer e adaptar-se à realidade da criança retardada. (p. 37)

As relações iniciais estão comprometidas em alguns pontos referentes ao desejo dos pais. Segue-se um questionamento sobre o futuro do filho; o 
que ele poderá ou não, alcançar em termos e desenvolvimento. No campo da sexualidade não é diferente. Alguns mitos sobre a sexualidade do deficiente mental dizem respeito à garota se tornar promiscua ou vítima de abuso sexual enquanto que o garoto poderia se tornar um tarado ou sofrer abusos homossexuais.

A sexualidade da pessoa com deficiência, segue, apesar de algumas dificuldades, o curso de desenvolvimento de uma pessoa comum. Um desenvolvimento equilibrado não pode desprezar a construção da sexualidade. Manifestações sexuais devem acontecer num contexto de atitudes positivas que demonstrem aceitação e carinho. "Quando um indivíduo cresce num ambiente hostil e repressor a manifestações sexuais é muito provável que ele desenvolva sentimentos de negação e intolerância à sua própria sexualidade". (Reche, 199-). Facilmente é interdito pelos pais os questionamentos de cunho sexual. Crianças com deficiência mental fazem poucas perguntas acerca da sexualidade se comparadas a crianças comuns.

Tal interdição funciona como uma trava da fantasia e das aspirações quanto ao futuro. Então, só resta a esta criança esperar para o futuro aquilo que já conquistou no presente, ou seja, uma condição infantil, uma exclusão adulto "normal", e um aprisionamento em seu corpo e na realidade de sua deficiência que, impedida de ser simbolizada nos aspectos possiveis, passa a ser, ela própria, o Real. (Schimidt, 1998, p. 39).

A manutenção pelos pais de um padrão infantil de sexualidade para o deficiente mental foi um dos temas discutido por Giamia e D'Allones (1984). Ao entrevistarem pais e profissionais concluíram que a visão de ambos sobre a sexualidade do deficiente mental era diferente. Enquanto os profissionais percebiam a sexualidade dos alunos como selvagem e incompleta, por não controlarem seus impulsos nem chegarem ao coito, os pais viam os filhos como infantis, apresentando somente manifestações de carinho e afeto.

Facion apud Militão (1991) enfatiza que dentre as manifestações de sexualidade mais observadas por professores que lidam com alunos deficientes mentais, pode-se destacar as práticas masturbatórias individuais e coletivas, exibicionismo e voyeurismo. Para um profissional que carrega uma idéia padronizada sobre sexualidade, será muito difícil dar o limite daquilo que é socialmente aceitável sem transmitir também uma noção de que sexo é algo proibido.

$O$ grande erro dos profissionais que trabalham com deficientes mentais é usar como referencial suas próprias expectativas para solucionar questões desta natureza, sem levar em conta que a sexualidade no deficiente se desenvolve em contextos diversos, 
a partir de experiências distintas [...] A melhor maneira de lidar com o deficiente é despir-se dos próprios preconceitos. (Gherpelli, 1995, p. 12).

Glat (1992) lembra que para orientar um jovem em relação a sexo:

É fundamental termos a nossa própria sexualidade já resolvida para não corrermos o risco de racionalizar nossas dificuldades ou repressões internas, transformando-as em valores morais preconceituosos, que serão por sua vez transmitidos àqueles que vem em busca de nossa orientação. (p. 72)

O orientador sexual precisa ampliar a dimensão que possui sobre sexualidade, principalmente no contexto de deficiência. É preciso ousar no campo da sensorialidade, extraindo prazer das pequenas coisas.

A sexualidade é um elemento importante da sensorialidade, entretanto, é um elemento num conjunto maior [...] desenvolver sensorialidade é trabalhar com a sexualidade os pensamentos, as emoções, o tato, o olfato, a afetividade, o relacionamento humano. É um universo interno a ser explorado. (Berti, 1998, p. 15).

Um dos desafios ao se trabalhar sexualidade e deficiência é a compreensão, por parte de pais e educadores de que "sexualidade independe de deficiência, seja ela física ou mental” (Lipp, 1988, p. 7). A sexualidade do deficiente é carregada de repressão e incompreensão. Mas cognição e sexualidade não estão necessariamente correlacionadas. Por isso, não é de admirar que, como as pessoas comuns, a pessoa com SD tenha interesse na aproximação com o outro que inclua contato físico, sexo e afeto. Não existem dados que comprovem seu menor ou maior interesse sexual. Lipp (1988) diz que os deficientes mentais têm impulsos sexuais iguais aos das outras pessoas.

Parte do que o jovem introjetar sobre sexualidade estará condicionado às reações que seus pais e/ou educadores terão diante de uma manifestação sexual. Pueschel (1998) defende uma postura aberta diante do desenvolvimento sexual como um todo. Assim é possível falar sobre menstruação e higiene, ejaculação noturna e prazer, auto-estima, capacidade reprodutiva e contracepção, namoro e responsabilidades na área da sexualidade. Sobre a SD, Freire (1998) comenta:

A principal dificuldade na expansão da sexualidade é a manutenção de um padrão infantil da sexualidade. Esta não se diferencia completamente tanto no sentido de genitalização, quanto no sentido de definição do parceiro. Muitas vezes o menino pode gostar de ser tocado e acariciado tanto por meninos, quanto meninas (e vice-versa), e isto não implica instauração de 
um padrão homossexual [...] A relação sexual geralmente não ocorre, e quando ocorre não é totalmente integrada como tal, podendo ser vista como uma brincadeira especialmente prazerosa e até engraçada [...] $O$ ambiente também é um fator impeditivo: a pessoa com $S D$, mesmo que possa atingir um alto grau de maturidade e independência é, na maioria das vezes, considerada como uma eterna criança pura - um anjo. E como tal, o seu grupo geralmente não viabiliza e até impede o desenvolvimento deste aspecto da sua personalidade. (p. 91)

E a pessoa com SD, o que pensa sobre si mesma? Juralinsky (1998) escrevendo sobre a síndrome relata a seguinte fala de um rapaz de 25 anos (SD): "Não me discriminam. Só não consideram importante o que faço". (p. 33). Geralmente os trabalhos nessa área pouco se preocupam, com a opinião daqueles que são "objeto de estudo". É necessária uma revisão dos conceitos até agora estabelecidos nas práticas clínica e educacional.

Ao conviver com a pessoa deficiente mental é imprescindível o reconhecimento da sua condição de ser sexuado, pois "assumir que o homem ou a mulher deficientes são assexuados por sua incapacidade é insultar sua condição de seres humanos" (Stewart apud Lopes, 1993, p. 289). Não se quer dizer com isso que a sexualidade da pessoa com deficiência mental é exatamente igual a de uma pessoa comum. Aliás, tratar os diferentes como iguais é a maior injustiça que se pode praticar.

Não se deve igualar a sexualidade das pessoas como um todo, nascidas em lugares diferentes, com histórias de vida variadas. É possível, contudo, abandonar os próprios preconceitos e entender a sexualidade da pessoa com SD como uma expressão natural da sua experiência vivencial. Desse modo, ao lidar com estes indivíduos diante de situações nas quais o comportamento sexual é mais evidenciado perceber-se-á a pessoa como um todo, onde obviamente, a sexualidade terá sua participação.

\section{REFERÊNCIAS BIBLIOGRÁFICAS}

ALBUQUERQUE, L.; RAMALHO, C. A Era do Respeito. Marie Claire, n. 99, Jun. 1999.

ANTONARAKIS, S. E.; The Down Syndrome Collaborative Group. Parental origin of the extra chromosome in trisomy 21 as indicated by analysis of DNA polymorphisms. The New Engl. J. Med. 324 (13): 872-876, 1991.

ASSUMPÇÃO JR., F. B.; SAPROVIERI, M. H. Sexualidade e Deficiência Mental, São Paulo: Moraes, 1987.

BAIRD, P. A.; SADOVNICK, A. D. Life tables for down syndrome. Hum. Genet. 82:291-292, 1989.

BARNARD, K.; ERICKSON, M. L. Como educar crianças com problemas de desenvolvimento. Porto Alegre: Globo, 1978. 
BERTI, C., Simples Prazer. Viver Psicologia. v. IV, n. 42, p. 14-15, Out. 1998.

BROWN, R. L. (1993) Social life, dating and marriage. In: Nadel L.; Rosenthal D.

(Org.) Down Syndrome: living and learning in the community, New York: Wiley Liss, 43-49, 1995.

CASTILLA, E. E.; RITTLER, M.; DUTRA, M. G.; LOPEZ-CAMELO, J. S.; CAMPAÑA, H.; PAZ, J. E.; ORIOLI, I. M.; ECLANC - Downsurv Groups. Survival of Children with Down Syndrome in South America Am. J. Med. Genet. 79: 000-000, 1998.

CONNOR, M.; FERGUNSON-SMITH, M. Essential Medical Genetics. 5. ed., United Kingdon: Blackwell Science, 1997.

COOLEY, C. W.; GRAHAM JR., J. M. Down Syndrome - An update and review for the primary pediatrician. Clin. Pediatr. 30:233-253, 1991.

DOWN, J. L. Observations on the Ethnic - Classification of Idiots. Lond. Hosp. Clin. Lec. Rep. 3:259, 1866.

EDWARDS, J. P., Adolescência e Vida Adulta. In: Siegfried Pueschel (Org.), Sindrome de Down: Guia para Pais e Educadores. 3. ed., Campinas, SP: Papirus, 1998.

FREIRE, Y. Síndrome de Down e Sexualidade. Saúde, Sexo e Educação, v. 4, n. 14, Jul./Ago./Set. 1998.

FREUD, S. Obras Completas. v. 1. Madrid: Nueva, 1967.

GELEHRTER, T. D.; COLLINS, F. S., Fundamentos de Genética Médica. Rio de Janeiro: Guanabra Koogan, 1992.

GHERPELLI, M. H. B. V. Diferente mas não Desigual: A Sexualidade do Deficiente Mental. São Paulo: Gente, 1995.

GIAMIA, A.; D'ALLONES, C. R. O Anjo e a Fera: Representações da Sexualidade dos Deficientes Mentais pelos Pais e Educadores. In: Maria D'Avila Neto (org.) A Negação da Deficiência: A Instituição da Diversidade. Rio de Janeiro: Achiamé/Socius, 1984.

GLAT, R. A Representação da Sexualidade dos Portadores de Deficiência Mental Segundo seus Relatos Pessoais. Revista Brasileira de Educação Especial, 1(1), p. 65-74, 1992.

GODEAU, P. (Produtor); DORMAEL, J. V. (Diretor). The Eight Day (Filme). Lumiére Latin America e Pan-Europlene Production, 1997.

JAGIELLO, G. Reproduction in Down Syndrome. In: De La Cruz F. F.; Gerad P. S. (eds.) Trissomy 21. Baltimore University Park Press, 151-162, 1981.

JERUSALINSK, A. O possível e impossível na cura da síndrome de Down. Manual do Curso de Capacitação de Recursos Humanos em Síndrome de Down: "da Segregação à Construção da Cidadania". Brasília-DF, 1998.

JOHANNISSON, R.; GROPP, A.; WINKING, H.; COERDT,W.; REHDER, H.; SCHWINGER, E. Down's syndrome in the male. Reproductive pathology and meiotic studies. Hum. Genet. 63: 132-138, 1983.

LAU, T. K.; FUNG, H. Y.; ROGERS, M. S.; CHEUNG, K. L. Racial variation in incidence of trisomy 21: survey of 57, 742 chinese deliveries. Am. J. Med. Genet. 75 (4): 386-8, 1998.

LEJEUNE, J.; GAUTIER, M.; TURPIN, R. Les chromosomes humains en culture de tissues. C. R. Acad. Sci. 248-602, 1959.

LIPP, M. N. Sexo para Deficientes Mentais: Sexo Excepcional Dependente e NãoDependente. 4. ed. São Paulo: Cortez, 1998. 
LOPES, G. Sexualidade Humana. 2. ed. Rio de Janeiro: Médsi, 1993

MILITÃ̃, A. C. A visão de pais e professores sobre a sexualidade de pessoas portadoras de deficiência mental. Dissertação (Mestrado em Educação) Centro de Educação e Humanidades, Universidade do Estado do Rio de Janeiro, 1991.

MOREIRA, L. M. A. A Sexualidade do Deficiente Mental: Um Mito em Questão. Sexus, v. 2, n. 2, p. 14-15, Mar./Abr. 1990.

MOREIRA, L. M. A. Considerações sobre aspectos genéticos e reprodutivos da síndrome de Down. In: Associação Baiana de Síndrome de Down (Ser Down), Informativo, n. 2, Nov. 1998.

MUSTACCHI, Z. Passado, presente e futuro - aspectos clínicos da Síndrome de Down - diagnóstico e perspectivas terapêuticas. Manual do Curso de Capacitação de Recursos Humanos em Síndrome de Down: "da Segregação à Construção da Cidadania". Brasília-DF, 1998.

PROJETO DOWN. Boletim. 16, 1992

PUESCHEL, S. (Org.) Síndrome de Down: Guia para Pais e Educadores. 3. ed., Campinas, SP: Papirus, 1998.

RECHE, C. C. A Sexualidade do Deficiente Mental. [S.L.: s.n.], 199-. (não consultado no original).

SCHMIDT, A. P. Comentários Sobre a Questão do Deficiente Mental. Manual do Curso de Capacitação de Recursos Humanos em Síndrome de Down: "da Segregação à Construção da Cidadania". Brasília-DF, 1998.

SHERIDAN, R.; LLERENA JR., J.; MATKINS, S.; DEBENHAM, P.; CAWOOD, A.; BOBROW, M. Fertility in a male with trisonomy 21. J. Med. Genet. 26: 294-298, 1989.

SMITH, D. W. Síndromes e Malformações Congênitas. 3. ed. São Paulo: Manole, 1985.

THOMPSON, M. W. Reproduction in two female mongols. Can. J. Genet. Cystol. 3:351-4, 1961.

WERNECK, C. Ninguém mais vai ser bonzinho na sociedade inclusiva. Rio de Janeiro: WVA, 1997.

ZÜHLKE, C.; THIES, V.; BRAULKE, J.; REIS, A.; SCHIRREN, C. Down syndrome and male fertility: PCR - derived fingerprinting, serological and andrological investigations. Clin. Genet. 46:324-326, 1994. 


\section{ANEXO}

Quadro 1: Combinação entre os Cromossomos de Pessoa com Trissomia 21 (SD) e outra Sem Alteração Cromossômica quando há Reprodução entre Elas.

\begin{tabular}{|c|c|c|}
\hline GAMETAS & \multicolumn{2}{|c|}{ PESSOA COMUM $(\mathrm{X} \mathrm{X})$} \\
\hline $\begin{array}{c}\text { TRISSOMIA } 21 \\
(\mathrm{X} X \boldsymbol{X})\end{array}$ & $\mathrm{X}$ & $\mathrm{X}$ \\
\hline $\mathrm{X}$ & $\underset{25 \% \text { de filhos comuns }}{\text { X X }}$ & $\underset{25 \% \text { de filhos comuns }}{\text { X X }}$ \\
\hline $\mathrm{X} \boldsymbol{X}$ & $\underset{\substack{\text { 25\% de filhos com } \\
\text { trissomia } 21(\mathrm{SD})}}{\mathrm{X} X \boldsymbol{X}}$ & $\underset{\substack{25 \% \text { de filhos com } \\
\text { trissomia } 21 \text { (SD) }}}{X X X}$ \\
\hline
\end{tabular}

Quadro 2: Combinação entre os Cromossomos de Casal com Trissomia 21 (SD) quando há Reprodução entre o Mesmo.

\begin{tabular}{|c|c|c|}
\hline GAMETAS & \multicolumn{2}{|c|}{ TRISSOMIA $21(\mathrm{X}$ X X) } \\
\hline $\begin{array}{l}\text { TRISSOMIA } 21 \\
(\mathrm{X} X \boldsymbol{X})\end{array}$ & $\mathrm{X}$ & $\mathrm{X} X$ \\
\hline $\mathrm{X}$ & $\underset{25 \% \text { de filhos comuns }}{\mathrm{X} \mathrm{X}}$ & $\begin{array}{c}\underset{\text { 25\% de filhos com }}{\mathrm{X} \boldsymbol{X}} \\
\text { trissomia } 21(\mathrm{SD})\end{array}$ \\
\hline $\mathrm{X} \boldsymbol{X}$ & $\underset{\substack{25 \% \text { de filhos com } \\
\text { trissomia } 21(\mathrm{SD})}}{\mathrm{X} \boldsymbol{X}}$ & $\underset{\text { 25\% de filhos com }}{\mathrm{X} X \boldsymbol{X} \boldsymbol{X}}$ \\
\hline
\end{tabular}

